\title{
Parenteral Nutrition in Advanced Cancer: The Healthcare Providers' Perspective
}

\author{
Trude R. Balstad (10 · Erik T. Løhre · Lene Thoresen • Morten Thronæs • \\ Laila S. Skjelvan · Ragnhild G. Helgås · Tora S. Solheim • \\ Kari Sand
}

Received: January 20, 2022 / Accepted: February 8, 2022 / Published online: February 24, 2022

(c) The Author(s) 2022

\begin{abstract}
Introduction: The evidence base for parenteral nutrition (PN) in advanced cancer patients is limited. We studied healthcare providers' (HCPs') experiences with PN in cancer patients, focusing on perceived treatment benefits and challenges.
\end{abstract}

Methods: An 18-item online survey was emailed to HCPs attending one of three regional palliative care seminars held within a 6-month period. The survey included single-response items, multiple-response items, and free text

Supplementary Information The online version contains supplementary material available at https:// doi.org/10.1007/s40487-022-00189-1.

T. R. Balstad $(\bowtie) \cdot$ E. T. Løhre · M. Thronæs

R. G. Helgås · T. S. Solheim · K. Sand

Department of Clinical and Molecular Medicine, Faculty of Medicine and Health Sciences, NTNU, Norwegian University of Science and Technology, Trondheim, Norway

e-mail: trude.r.balstad@ntnu.no

T. R. Balstad · E. T. Løhre · L. Thoresen ·

M. Thronæs - L. S. Skjelvan · R. G. Helgås .

T. S. Solheim · K. Sand

Cancer Clinic, St. Olavs Hospital, Trondheim

University Hospital, Trondheim, Norway

E. T. Løhre

e-mail: erik.t.lohre@ntnu.no

M. Thronæs

e-mail: morten.thrones@ntnu.no boxes concerning PN. Descriptive statistics and qualitative thematic content analysis were applied.

Results: One hundred and two seminar participants completed the survey. Ninety-three percent were female, $86 \%$ were nurses/oncological nurses, and $80 \%$ worked in primary care. Respondents reported a well-functioning collaboration across levels of care. They perceived that PN may increase the patients' level of energy, improve the general condition, and reduce eating-related distress. On the downside, HCPs observed burdensome side effects, that the treatment was resource-demanding, and that decisions on PN withdrawal were difficult.
L. S. Skjelvan
e-mail: laila.skjelvan@stolav.no
R. G. Helgås
e-mail: ragnhild.g.helgas@ntnu.no
T. S. Solheim
e-mail: tora.s.solheim@ntnu.no
L. Thoresen
National Advisory Unit on Disease-Related
Malnutrition, Oslo University Hospital, Oslo,
Norway
e-mail: lene.thoresen@stolav.no
K. Sand
Department of Health Research, SINTEF Digital,
Trondheim, Norway
e-mail: kari.sand@sintef.no 
Conclusion: The study results are based on the perspectives of more than 100 HCPs with comprehensive clinical experience with $\mathrm{PN}$. Their knowledge represents an important experience base for improvement of healthcare services and advanced care planning.

Keywords: End-of-life care; Healthcare provider; Palliative cancer care; Parenteral nutrition

\section{Key Summary Points}

Given the limited evidence base for the benefit of parenteral nutrition (PN) treatment in advanced cancer, healthcare providers' knowledge represents an important experience base for improvement of healthcare services and advanced care planning.

What are healthcare providers' experiences with PN in cancer patients, with special attention towards perceived treatment benefits and challenges?

Respondents perceived that PN increases the patients' level of energy, improves their general condition, and reduces eating-related distress.

On the downside, healthcare providers observed burdensome side effects, that the treatment was resource-demanding, and that decisions on PN withdrawal were difficult.

\section{INTRODUCTION}

Food consumption is not only driven by a desire for nutrients and satiety; meals are also fundamental elements of human interaction and culture [1]. For patients with advanced cancer suffering from organ dysfunction and/or gastrointestinal tract obstruction as well as critically low food intake, malnutrition represents an overriding threat to survival [2-5]. A balanced and sufficient nutritional intake is essential to support body functions and ensure growth and maintenance [6]. A negative energy balance might be caused by reduced appetite, but also symptoms such as dry mouth and taste changes, nausea and vomiting, constipation, and early satiety [7]. With reduced food intake, medical considerations regarding nutritional support, such as parenteral nutrition (PN), must be addressed [6].

Few studies have demonstrated subjective or objective benefits of $\mathrm{PN}$ in patients with advanced cancer [8]. Thus, healthcare providers (HCPs) have little evidence to guide decisionmaking, practical administration, and evaluation of this intervention [6, 8]. For palliative cancer care, guidelines only provide general recommendations, leaving HCPs with difficult decisions on initiation and duration of PN [6]. Lack of guidance and conflicting views can result in unresolved medical and ethical dilemmas like fear of starvation and abandonment $[9,10]$. Palliative care physicians may refrain from recommending $\mathrm{PN}$ towards the end of life due to the lack of evidence of meaningful benefit and the potential side effects and invasive nature of the intervention $[11,12]$. On the other hand, physicians less familiar with palliative care may be more prone to recommend medical nutrition and even to consider its withdrawal as actively causing the patient's death [13, 14]. Oncologists may feel a reluctance to disclose unfavorable medical information to cancer patients and may feel the need to preserve patient hope [15]. Interestingly, the most difficult conversations are reported to be those dealing with lack of additional treatment options, and one out of five oncologists reported occasional administration of presumably ineffective treatment in order to maintain patient hope [16].

Many patients continue PN at home after its initiation in the hospital [17]. Palliative care patients often wish to spend as much time as possible at home, and a close collaboration across levels of care is needed to ensure PN treatment quality [18]. Care interventions must be appropriate and not wasteful, and avoiding excess use of treatment is important for promoting quality in healthcare services [19, 20]. The dynamic nature of palliative cancer care 
implies that once beneficial interventions might represent futile treatment later in the disease trajectory [21]. An adequate decisionmaking process regarding dose adjustments and treatment continuation or discontinuation is dependent on hands-on observations of perceived effects and side effects.

Given the limited evidence base for the benefit of PN treatment in palliative cancer care, HCPs' day-to-day experiences and observations contribute to the body of knowledge. Against this background, we aimed to explore HCPs' opinions on collaboration and decision-making across levels of care, and their perceptions of benefits and challenges with PN in advanced cancer care.

\section{METHODS}

The study was designed, executed, and reported in accordance with the Checklist for Reporting Results of Internet E-Surveys (CHERRIES) [22].

\section{Setting}

Over a 6-week period in 2018, a survey was performed in Mid-Norway among HCPs after attending regional palliative care educational seminars, held at three different locations. Cachexia and nutrition in palliative care was one of the topics at the educational seminar by experienced palliative care clinicians and researchers. Lectures covering evidence-based guidelines and clinical challenges with $\mathrm{PN}$ in advanced cancer were given. Discussions after the lectures were based on participants' comments and experiences.

\section{Questionnaire}

The author group developed an 18-item online survey. The questionnaire was piloted and updated for usability and functionality, clinical relevance and reliability, and face validity at the Palliative Care Unit, St. Olavs hospital, Trondheim University Hospital, Norway, and at a nearby community palliative care unit. The survey consisted of the following sections: demographics (five items), experiences and competence (six items), decision processes (five items), and an opportunity to provide additional comments (one item). There was a combination of single-response items, multipleresponse items, and free text boxes.

\section{Sample}

The survey was emailed to 304 HCPs. The first item contained a qualifying question: "Do you have personal experience with parenteral nutrition in palliative cancer care?" (yes/no) (Supplementary Material). Only "yes" responders were able to complete the survey. One reminder was emailed to non-responders after 2 weeks and the survey was closed 4 weeks thereafter.

\section{Data Quality}

The survey was open, in the sense that email recipients had access to the questionnaire. There were no mandatory responses or adaptive questioning. The participants could review and alter their answers before submission. The responses were exported to a database and checks for duplicates were performed manually, without using Internet Protocol (IP) addresses and $\log$ files.

\section{Analyses}

Descriptive statistics were used for participant demographics and multiple-response items. The results are displayed as frequencies and percentages. Means were used as a measure of central tendency, and range and standard deviations (SDs) as measures of dispersion.

Free text responses were analyzed qualitatively using thematic analysis, a method for identifying thematic patterns in the participants' stated opinions [23]. The analysis is based on the informants' responses to four of the five free text items in the questionnaire (the fifth item was omitted due to limited content). For two of the items, 88 responses were provided, and for the other two, 68 and 71 responses were provided. A free text response in this survey typically consisted of one 
Table 1 Identified categories from the thematic analysis of free text responses

\begin{tabular}{|c|c|c|}
\hline Free text item & Identified categories & Illustrative quotes \\
\hline \multirow{4}{*}{$\begin{array}{l}\text { How do you perceive the collaboration across levels of } \\
\text { care when a patient is discharged from the hospital } \\
\text { with PN? }\left({ }^{*} n=88 \text { responses }\right)\end{array}$} & \multirow[t]{2}{*}{$\begin{array}{l}\text { Well-functioning } \\
\text { collaboration }\left({ }^{* *} n=54\right)\end{array}$} & $\begin{array}{l}\text { 'The collaboration is almost always good. The palliative team is a } \\
\text { great resource' (Local hospital) }\end{array}$ \\
\hline & & $\begin{array}{l}\text { 'We get assistance from the hospital when we need it' } \\
\text { (Community) }\end{array}$ \\
\hline & \multirow[t]{2}{*}{$\begin{array}{l}\text { Treatment plan at discharge } \\
\quad\left({ }^{* *} n=16\right)\end{array}$} & $\begin{array}{l}\text { 'Often, a plan for duration and withdrawal of treatment is } \\
\text { lacking' (Community) }\end{array}$ \\
\hline & & $\begin{array}{l}\text { 'Sometimes we receive a plan, sometimes we do not' } \\
\text { (Community) }\end{array}$ \\
\hline \multirow[t]{5}{*}{$\begin{array}{l}\text { What are your positive experiences with PN to cancer } \\
\text { patients? }\left({ }^{*} n=71 \text { responses) }\right.\end{array}$} & \multirow[t]{2}{*}{$\begin{array}{l}\text { Improved general condition } \\
\quad\left({ }^{* *} n=30\right)\end{array}$} & $\begin{array}{l}\text { 'Improved general condition, stable weight/weight gain, can } \\
\text { handle other treatment better' (University hospital) }\end{array}$ \\
\hline & & $\begin{array}{l}\text { 'Weight gain, better nourished, improved general condition' } \\
\text { (Community) }\end{array}$ \\
\hline & $\begin{array}{l}\text { Improved quality of life } \\
\quad\left({ }^{* *} n=22\right)\end{array}$ & $\begin{array}{l}\text { 'The patients feel that they gain energy, they do not have to exert } \\
\text { themselves by eating (...) and then there is hope... important } \\
\text { when it comes to quality of life" (Community) }\end{array}$ \\
\hline & \multirow{2}{*}{$\begin{array}{l}\text { Possibilities for prolonged } \\
\quad \text { life }\left({ }^{* *} n=16\right)\end{array}$} & 'Hope of prolonging the life worth living' (Local hospital) \\
\hline & & $\begin{array}{l}\text { 'I think that cancer patients who have received parenteral } \\
\text { nutrition live a bit longer' (Community) }\end{array}$ \\
\hline \multirow[t]{9}{*}{$\begin{array}{l}\text { What are your negative experiences with } \mathrm{PN} \text { to cancer } \\
\text { patients? }\left({ }^{*} n=68 \text { responses }\right)\end{array}$} & \multirow[t]{3}{*}{$\begin{array}{l}\text { Resource-demanding } \\
\quad\left({ }^{* *} n=20\right)\end{array}$} & $\begin{array}{l}\text { 'The patient is surrounded by a lot of clinical procedures instead of } \\
\text { caregiving' (Community) }\end{array}$ \\
\hline & & $\begin{array}{l}\text { 'Administration of parenteral nutrition occupies a lot of the } \\
\text { patients' time. Creates a need for several visits from home care } \\
\text { services and equipment in the patients' home' (University } \\
\text { hospital) }\end{array}$ \\
\hline & & "It's very resource-demanding for the municipality" (Community) \\
\hline & \multirow{3}{*}{$\begin{array}{l}\text { Side effects, complications, } \\
\text { or discomfort/ } \\
\text { inconvenience } \\
\left({ }^{* *} n=32\right)\end{array}$} & "It causes nausea, vomiting and discomfort' (Community) \\
\hline & & $\begin{array}{l}\text { "Most patients who get the treatment at home, prefer to receive it } \\
\text { in the evening or night. This leads to quite a few visits and } \\
\text { disturbed sleep' (Local hospital) }\end{array}$ \\
\hline & & $\begin{array}{l}\text { "A lot of side effects, which cause poor quality of life" } \\
\text { (Community) }\end{array}$ \\
\hline & \multirow{3}{*}{$\begin{array}{l}\text { Difficulties related to } \\
\text { termination of treatment } \\
\left({ }^{* *} n=28\right)\end{array}$} & $\begin{array}{l}\text { "Difficult to terminate, it destroys hope of life for both the patient } \\
\text { and the family" (Community) }\end{array}$ \\
\hline & & $\begin{array}{l}\text { "It is very difficult for physicians to make the decision about } \\
\text { termination at the end of life" (Community) }\end{array}$ \\
\hline & & $\begin{array}{l}\text { "Obviously to terminate. When treatment is initiated, it is difficult } \\
\text { to withdraw it" (Local hospital) }\end{array}$ \\
\hline \multirow[t]{5}{*}{$\begin{array}{l}\text { How do you perceive patients' and relatives' reactions to } \\
\text { PN treatment termination? }\left({ }^{*} n=88 \text { responses }\right)\end{array}$} & \multirow[t]{2}{*}{ Acceptance $\left({ }^{* *} n=31\right)$} & $\begin{array}{l}\text { "Most patients and relatives accept it after some consideration" } \\
\text { (Local hospital) }\end{array}$ \\
\hline & & $\begin{array}{l}\text { "If patient and their next of kin get an explanation they manage to } \\
\text { comprehend, most of them react with understanding' } \\
\text { (Community) }\end{array}$ \\
\hline & \multirow[t]{3}{*}{ Mixed feelings $\left({ }^{* *} n=30\right)$} & $\begin{array}{l}\text { 'The initial reactions are emotional, but after good } \\
\text { communication with doctor, nurse and the involved parties, it's } \\
\text { fine' (Community) }\end{array}$ \\
\hline & & "Despaired, but also relieved" (Community HCP) \\
\hline & & $\begin{array}{l}\text { 'Sometimes, there's a mismatch between the perspective of the } \\
\text { family and the patient' (Community HCP) }\end{array}$ \\
\hline
\end{tabular}


Table 1 continued

\begin{tabular}{|c|c|c|}
\hline Free text item & Identified categories & Illustrative quotes \\
\hline & \multirow[t]{3}{*}{$\begin{array}{l}\text { Good information essential } \\
\quad \text { for acceptance } \\
\left.\quad{ }^{* *} n=41\right)\end{array}$} & $\begin{array}{l}\text { "I experience that the patient and the family accept the decision. It } \\
\text { takes a lot of information and continuous monitoring of the } \\
\text { need for PN treatment. A good dialogue with the treating } \\
\text { physician makes the decision easier to accept" (University } \\
\text { hospital) }\end{array}$ \\
\hline & & $\begin{array}{l}\text { 'If the topic is addressed early in the trajectory, it's easier to } \\
\text { terminate' (Community HCP) }\end{array}$ \\
\hline & & $\begin{array}{l}\text { "I experience that the relatives need several explanations, but when } \\
\text { they understand the reason for termination, it's okay" } \\
\text { (Community) }\end{array}$ \\
\hline
\end{tabular}

${ }^{*} n$ indicates number of responses

${ }^{* *} n$ indicates number of responses on which each category is based. Total number of responses for each category could be lower or higher than the total number of responses to the item due to multiple topics in a single response, responses addressing topics not included in the analyses, or uninterpretable response

or two sentences (e.g., one response to the question about perceived positive experiences with $\mathrm{PN}$ treatment was "The patient could stay at home during treatment, and we get to practice intravenous therapy") or were written in a key word format (e.g., one response to the question about perceived negative experiences of PN was "nausea, diarrhea"). The thematic analysis was conducted separately for the responses of each free text item, and consisted of the following steps: (1) reading all responses provided to each valid item to get an overall impression of the topics represented, (2) iteratively identifying a set of codes for detailed coding of the topics represented in the responses, (3) coding all responses, (4) collating the content of the responses into groups identified by code, (5) identifying thematic patterns, (6) merging adjacent code groups based on these patterns, and (7) writing thematic condensates. The condensates are presented in the Results section. The main themes and illustrative quotes are presented in Table 1 . The quotes are chosen to reflect a diversity of views from all respondent groups. All condensates are based solely on the participants' answers and do not contain any author interpretation of latent content. The Norwegian terms and expressions were translated.

\section{Ethics}

In the invitation email, potential participants were informed that their responses were to be anonymized and treated with confidentiality.
No personal data or Internet Protocol (IP) addresses were registered. Storage of data in the online survey was System and Organization Controls-2 (SOC 2)-accredited and certified by International Organization for Standardization (ISO) 27001. Completion of the survey was regarded as consent to participate. Approval from the Regional Committee for Medical and Health Research Ethics was not required, as the study was beyond the scope of the Norwegian Health Research Act [24]. Researchers responsible for analyzing the survey results (TRB and KS) were blinded to email lists and conference participants.

\section{RESULTS}

\section{Survey Respondent Characteristics}

One hundred thirty-five (44\%) of the 304 email recipients responded. Out of the 135 respondents, 102 (76\%) reported personal experience with $\mathrm{PN}$ in palliative cancer care and completed the survey. The mean age (SD) of those who completed the survey was 46 (10) years and the vast majority $(n=95,93 \%)$ were female (Table 2$)$. The majority $(n=87,86 \%)$ were certified nurses or oncology nurses. Thirty-one percent were employed in nursing homes/care facilities and $38 \%$ in home care services (Table 2). Eighty-five percent of the HCPs followed up to ten PN patients yearly, and more 
Table 2 Participant characteristics

\begin{tabular}{ll}
\hline Variables & $n=\mathbf{1 0 2}$ \\
\hline Age, years, mean (SD) & $45.7(10)$ \\
Sex, $n$ (\%) & $95(93)$ \\
Women & \\
Healthcare profession, $n$ (\%) & $8(8)$ \\
Healthcare professionals & \\
(vocational training) & \\
Oncological nurse & $38(37)$ \\
Nurse (including other specialties & $49(48)$ \\
than oncology) & $1(1)$ \\
Physician & $13(13)$ \\
Clinical dietician & $1(1)$ \\
Specialist oncology & $1(1)$ \\
physiotherapist & \\
Missing &
\end{tabular}

$n$ number of participants; $S D$ standard deviation

${ }^{*}$ Assistant nurses, auxiliary nurses, and care workers

than 50\% had administered PN the last 6 months (Table 3).

\section{Thematic Categories Identified}

The free text responses were grouped and categorized as displayed in Table 1 . The number of responses for each identified category is indicated.

\section{Collaboration Between Community Healthcare and Hospitals}

A well-functioning collaboration was the most frequent description of community and hospital care interaction for patients discharged with $\mathrm{PN}$, reported by more than half of the respondents $(54 / 88)$. A well-functioning collaboration was described as easily accessible regular dialogue with hospital palliative care teams or other personnel with PN expertise, available necessary equipment, and the presence of a preplanned treatment schedule. Twenty-two informants addressed the existence of a PN treatment schedule at patient discharge from hospital. Fifteen of them stated that no such plan was available and four that it was. (The remaining answers did not specify whether a plan was provided.)

\section{Perceived Benefits of PN: Improved General Condition, Quality of Life, Well- Being, and Hope}

Seventy-one responses were provided for this item. The most frequently reported positive experience with PN for advanced cancer patients was improved general condition (30 of 71 responses). The respondents claimed that PN gives the patients more energy, vitality, and muscular strength. According to some respondents, this may provide an opportunity for a more meaningful and active life (9/71), and the possibility for more time spent at home (8/71).

The second most frequently reported perceived benefit of PN was improved quality of life (in 22 of 71 responses). Improved quality of life was exemplified by increased levels of energy, ability to stay at home, and hope in general. In addition, 11 of the 71 respondents claimed that $\mathrm{PN}$ reduces eating-related distress and discomfort. The respondents stated that PN makes both patients and next of kin more at ease as the nutritional needs are covered, ultimately affecting the home atmosphere positively. Furthermore, four respondents claimed that PN 
Table 3 Participants' experience with parenteral nutrition

\begin{tabular}{|c|c|}
\hline Variables & $n=102$ \\
\hline Have you been certified/recertified to use & $n(\%)$ \\
\hline \multicolumn{2}{|l|}{ PN infusion pump during the last 3 years? } \\
\hline Yes, $n(\%)$ & $31(30)$ \\
\hline Oncology nurse & $14(45)$ \\
\hline Physician & $1(3)$ \\
\hline Nurse (other than oncology nurses) & $16(52)$ \\
\hline No, $n(\%)$ & $71(70)$ \\
\hline $\begin{array}{l}\text { Healthcare professionals (vocational } \\
\text { training)* }\end{array}$ & $8(11)$ \\
\hline Oncological nurse & $24(34)$ \\
\hline Physician & $3(4)$ \\
\hline Nurse (other than oncology nurses) & $34(48)$ \\
\hline Clinical dietician & $1(1)$ \\
\hline Specialist oncology physiotherapist & $1(1)$ \\
\hline \multicolumn{2}{|l|}{ Where have you had experience with cancer } \\
\hline Hospital & $9(9)$ \\
\hline Patients' homes & $30(29)$ \\
\hline Nursing home/care facilities & $19(19)$ \\
\hline Hospital and patients' homes & $9(9)$ \\
\hline Hospital and nursing home/care facilities & $12(12)$ \\
\hline $\begin{array}{l}\text { Patients' homes and nursing home/care } \\
\text { facilities }\end{array}$ & $10(10)$ \\
\hline Missing & $2(2)$ \\
\hline \multicolumn{2}{|l|}{ Approximately how many patients receiving PN } \\
\hline 0 & $6(6)$ \\
\hline $1-5$ & $67(65)$ \\
\hline $6-10$ & $14(14)$ \\
\hline $11-15$ & $4(4)$ \\
\hline $16-20$ & $3(3)$ \\
\hline$>20$ & $5(5)$ \\
\hline Missing & $3(3)$ \\
\hline
\end{tabular}

Table 3 continued

\begin{tabular}{ll}
\hline Variables & $n=\mathbf{1 0 2}$ \\
\hline When did you last administer PN & \\
to a cancer patient? & $18(18)$ \\
During last week & $16(16)$ \\
During last month & $21(21)$ \\
During last 6 months & $18(17)$ \\
During last year & $26(25)$ \\
Longer than a year ago & $3(3)$ \\
Missing &
\end{tabular}

$n$ number of participants; $P N$ parenteral nutrition

*Assistant nurses, auxiliary nurses and care workers

reduces eating-related nausea and vomiting and thus increases the patients' well-being.

The third main category of HCP-reported positive $\mathrm{PN}$ experiences was related to the possibility for prolonged life. The subject was addressed in 16 of the 71 responses and was strongly connected to hope, as exemplified by the response from a nursing home employee: "The belief that fluid and nutrition is life-giving, gives hope to many patients and relatives."

Perceived Disadvantages of PN:

A Resource-Demanding Treatment, with Considerable Side Effects and Difficult Decisions on Treatment Withdrawal

Sixty-eight respondents answered this item. Twenty out of the 68 respondents considered $\mathrm{PN}$ to be resource-demanding treatment for the patient, the family, and the healthcare system, due to the time-consuming dependency of equipment, training, and HCPs' assistance. For instance, the respondents stated that the patient's home may appear more like a hospital invaded by equipment and professionals. Additionally, eight respondents highlighted that PN usually limits the patients' mobility and restricts their possibility for an active life.

Almost half of the responses about negative experiences with PN (32/68) addressed side 
effects, complications, or discomfort. According to HCP experiences, the most frequently experienced side effects were edema and nausea (mentioned in 16 and 14 responses, respectively). Vomiting, diarrhea, dyspnea, and pain were also reported as side effects experienced. Moreover, dyspnea, gastrointestinal side effects, and edema were the most commonly reported reasons for treatment withdrawal in the multiple-response item (Table 4).

Twenty-eight out of the 68 respondents addressed difficult decisions regarding treatment withdrawal. Although both approaches were common, abrupt PN treatment cessation was more frequently reported than treatment withdrawal preceded by a gradual dose reduction (Table 5). In the free text answers, respondents noted that optimizing the timing of treatment withdrawal was both an ethical and a medical dilemma. The fear that treatment withdrawal equals withdrawal of hope was counterbalanced by worry of providing nonbeneficial interventions, and fear of aggravating the dying phase. Additionally, in the free text

Table 4 When is intravenous nutrition terminated?

\begin{tabular}{ll}
\hline Variables $(\boldsymbol{n}=\mathbf{1 0 2})$ & $\boldsymbol{n}(\%)$ \\
\hline In the absence or cessation of effect, $n(\%)$ & 50
\end{tabular}

When patients have side effects 70

(e.g., dyspnea, GI side effects, edema), $n$ (\%)

Patients' wish, $n(\%)$

Wish from relatives, $n(\%)$

When patients have short expected survival, 68 $n(\%)$

Other reasons $(n=4)$

Advice from specialist healthcare service

1

Not involved in the process

Mixed reasons 2

Multiple options possible. Missing answer $=13$, valid percent presented

GI gastrointestinal
Table 5 How is parenteral nutrition terminated?

\begin{tabular}{ll}
\hline Variables & $\boldsymbol{n}=\mathbf{1 0 2}(\%)$ \\
\hline By gradual dose reduction, $n(\%)$ & $41(40)$ \\
After a treatment pause, $n(\%)$ & $20(20)$ \\
Without gradual dose reduction, $n(\%)$ & $55(54)$ \\
Other reasons $(n=12)$ & \\
No experience & 2 \\
Death & 1 \\
Uncertain & 1 \\
Mix of the above & 3 \\
Irrelevant answers & 5 \\
\hline
\end{tabular}

Missing answer $n=33$, valid percent presented

answers, respondents reported that neither patients nor relatives had received sufficient information about PN treatment withdrawal plans, including how, when, and why. One respondent highlighted the difficulties in initiating a discussion about PN treatment plans with patients and relatives who were unaware that treatment withdrawal was a realistic option, or who presumed that treatment was to be continued for the rest of the patient's life. Finally, HCPs reported that relatives often wanted PN treatment to be continued for a longer period than the patients did.

Patients' and Next of Kin's Responses to PN Treatment Withdrawal: Acceptance and Mixed Feelings, Possibly Diminished by Good Information

Eighty-eight responses to patients' and next of kin's reactions to $\mathrm{PN}$ treatment withdrawal were recorded. Thirty-one respondents (31/88) described acceptance, i.e., that the decision on PN treatment withdrawal was accepted by patients and relatives.

Thirty respondents (30/88) stated that the patients and relatives have mixed feelings regarding treatment withdrawal. While some accept the decision, understand the logical reasoning, and even feel relieved, others react with anger, anxiety, despair, or hopelessness. 
Also, a dynamic process of acceptance was described by some of the respondents, meaning that patients or relatives at first may not accept the decision of treatment withdrawal, but eventually reconcile with the situation. Reconciliation is reported to be dependent on information provided during an ongoing dialogue. Thirteen of the 88 responses addressed divergent reactions in patients and next of kin. Of these, 12 claimed that even though the patients accepted PN treatment withdrawal, their relatives did not.

In $41(41 / 88)$ of the responses about patients' and next of kin's reactions on PN treatment withdrawal, respondents stated that good information is essential for acceptance. Building a common understanding through shared decision-making was considered a success criterion for treatment withdrawal being the preferred option. According to the respondents, a good information process includes frequent and repeated consultations with a spacious time frame on the issue. Additionally, it was stated that more information on treatment cessation already at treatment initiation may prepare the ground for PN treatment withdrawal.

\section{DISCUSSION}

The data in this study represents comprehensive clinical experience with PN of more than 100 HCPs. The HCPs had a perception that PN improved the patients' general condition and quality of life, that the treatment was life-prolonging, and that patients were able to spend time at home and conduct preferred activities. On the downside, the HCPs stated that patients experienced PN treatment side effects, complications, or discomfort/inconvenience. In addition, $\mathrm{PN}$ is resource-demanding in terms of equipment, training, and professional assistance, and may furthermore result in difficult decision-making processes when it comes to treatment withdrawal.

Despite very few studies exploring HCPs', patients', and/or next of kin's perceptions regarding $\mathrm{PN}$ in advanced cancer, our findings are in accord with previously identified positive and negative features $[17,25,26]$. Patients with advanced cancer and their next of kin reported improved quality of life, energy level, and activity level associated with PN [17, 25]. In a study by Orrevall et al. [25], improved quality of life was related to the patients' and family members' feelings of relief and security when nutritional needs were met. In our study, quality of life was related to hope. The dimensions of relief, security, and hope are not necessarily covered in validated quality of life (QoL) measurements [27-29], and in clinical practice quality of life and impact of PN might sometimes be best expressed in patients' own words $[30,31]$.

Initiation and/or continuation of $\mathrm{PN}$, as well as the decision to withhold or withdraw PN, may be challenging for both the medical staff and patients' next of kin $[10,26,32]$. In our study, the participants described termination of $\mathrm{PN}$ as ethically challenging due to the strong association between nutrition and hope of prolonging life. This is also identified and discussed in previous research on HCPs', patients', and families' perceptions of $\mathrm{PN}$ treatment $[10,30,33]$. PN withdrawal may be particularly challenging due to potential moral, ethical, or religious feelings about the use of $\mathrm{PN}$ at end of life, the strong symbolism carried by food, and the perception that the patient starves to death if treatment is terminated $[30,33]$.

Interestingly, the patients and family members in the study by Orrevall et al. did not point out difficulties with termination of PN treatment as a particularly challenging aspect [25], as HCPs in our study did. However, HCPs in our study also described how they manage to achieve acceptance for treatment withdrawal among both patients and relatives and gave examples of what characterizes a good communication process. This shows that despite extensive challenges related to withdrawal of PN, HCPs have sufficient competence to contribute to a shared decision-making process that considers patients' and next of kin's emotions and perspectives.

In our study, HCPs reported that side effects and short expected survival were the most prevalent reasons for termination of $\mathrm{PN}$, and that PN was terminated without a gradual dose reduction. It is worth noting that the relatives' wishes were less frequently reported as a reason 
for termination compared to the patients' requests. Patients and next of kin might have different opinions on which care plan best serves the patient's interest. In a survey conducted among 499 bereaved family members of patients with cancer, $80 \%$ believed that $\mathrm{PN}$ and parenteral hydration was beneficial for the patients [32]. This is in accord with what some HCPs reported in our study, where relatives wanted prolonged PN treatment more often than the patients and did not realize that treatment could be terminated. HCPs need to inform patients and families about the evidence base for PN and explain why anorexia and weight loss become irreversible at some point, in order to avoid futile interventions at the end of life. Nevertheless, HCPs report high levels of ethical dilemmas due to lack of information and consensus associated with PN withdrawal, indicating a certain degree of helplessness and abandonment of care [10].

Although patients might consider family members' opinions to be crucial in making decisions regarding PN [26], few studies have addressed patients who receive $\mathrm{PN}$ in an advanced cancer care setting and investigated their beliefs and perceptions of the treatment and how this view might change over time. The most accurate perception of PN treatment can only be described by the patients themselves, and it is important to reduce any discrepancies between the different points of view (families/patients vs. professionals).

Despite the high response rate among the participants in this survey and the strength of a survey containing single-response and multipleresponse items as well as free text boxes, this study has several limitations. Firstly, the survey subjects were attending a palliative care seminar aiming to learn and educate themselves, which might reflect a selection of respondents. Secondly, the survey items contain the phrase "cancer patients" and not "advanced cancer patients" or "palliative cancer patients," since the definitions and understanding of these phrases may vary among HCPs [34]. Therefore, we do not know which patients the survey subjects had in mind when reporting their experiences. Nevertheless, HCPs in this study work primarily in nursing homes and home care services, where patients with advanced cancer are cared for. Thirdly, the study subjects were limited to Norwegian HCPs mainly working in primary healthcare in a single healthcare region, and thus cannot necessarily be generalized to other settings or internationally. Fourthly, there is no available validated tool for this purpose, and the questions can potentially be affected by acquiescence bias, which is a common form of measurement error in surveys. However, using a mixture of closed-ended and open-ended question formats might have reduced this risk. Fifthly, the respondents were mainly female and nurses, which introduces both a gender and HCP bias. Finally, translation of free text responses from Norwegian to English led to a thematic category named "quality of life," a phrase that should not be misinterpreted as the standardized concept of QoL, for which several validated measures exist within advanced cancer care and research.

\section{CONCLUSION}

HCPs reported a well-functioning collaboration across healthcare levels, indicating shared decision-making. The benefits of PN treatment were reported to be increased energy and improved general condition and quality of life for the patients, as well as reduced eating-related distress for the patients and their next of kin. The challenges of PN treatment were reported to be burdensome side effects for the patients; the resource demands that PN treatment imposes on patients, family, healthcare personnel, and the healthcare system; and the difficulty in ending treatment at the end of life.

\section{ACKNOWLEDGEMENTS}

The authors would like to thank the HCPs who contributed to the survey and shared their views and experiences. We also acknowledge the staff at the Regional Advisory Unit for Palliative Care in Central Norway for setting up and distributing the survey.

Funding. No funding or sponsorship was received for this study or publication of this 
article. The Journal's Rapid Service Fee was funded by the authors.

Authorship. All named authors meet the International Committee of Medical Journal Editors (ICMJE) criteria for authorship for this article, take responsibility for the integrity of the work as a whole, and have given their approval for this version to be published.

Author Contributions. Trude R. Balstad, Erik T. Løhre, Lene Thoresen, Morten Thronæs, Laila S. Skjelvan, Ragnhild G. Helgås, Tora S. Solheim, and Kari Sand have contributed equally towards the conception, design, drafting, review and approval of manuscript.

Disclosures. Trude R. Balstad, Erik T. Løhre, Lene Thoresen, Morten Thronæs, Laila S. Skjelvan, Ragnhild G. Helgås, Tora S. Solheim, and Kari Sand confirm that they have nothing to disclose.

Compliance with Ethics Guidelines. In the invitation e-mail, potential participants were informed that their responses were to be anonymized and treated with confidentiality. No personal data or IP addresses were registered. Storage of data in the online survey was SOC 2 -accredited and certified by ISO 27001. Completion of the survey was regarded as consent to participate. Approval from The Regional Committee for Medical and Health Research Ethics was not required, as the study was beyond the scope of the Norwegian Health Research Act (24). Researchers responsible for analyzing the survey results (TRB and KS) were blinded to e-mail lists and conference participants.

Data Availability. The datasets generated during and/or analyzed during the current study are available from the corresponding author on reasonable request.

Open Access. This article is licensed under a Creative Commons Attribution-NonCommercial 4.0 International License, which permits any non-commercial use, sharing, adaptation, distribution and reproduction in any medium or format, as long as you give appropriate credit to the original author(s) and the source, provide a link to the Creative Commons licence, and indicate if changes were made. The images or other third party material in this article are included in the article's Creative Commons licence, unless indicated otherwise in a credit line to the material. If material is not included in the article's Creative Commons licence and your intended use is not permitted by statutory regulation or exceeds the permitted use, you will need to obtain permission directly from the copyright holder. To view a copy of this licence, visit http:// creativecommons.org/licenses/by-nc/4.0/.

\section{REFERENCES}

1. Hamburg ME, Finkenauer C, Schuengel C. Food for love: the role of food offering in empathic emotion regulation. Front Psychol. 2014;5:32.

2. Cotogni P, Ossola M, Passera R, Monge T, Fadda M, De Francesco A, et al. Home parenteral nutrition versus artificial hydration in malnourished patients with cancer in palliative care: a prospective, cohort survival study. BMJ Support Palliat Care. 2020;12(1):114-20.

3. Pironi L, Boeykens K, Bozzetti F, Joly F, Klek S, Lal S, et al. ESPEN guideline on home parenteral nutrition. Clin Nutr. 2020;39(6):1645-66.

4. Liu M, Laskaratos FM, Bennell J, Chen J, Toumpanakis C, Mandair D, et al. Home total parenteral nutrition for intestinal failure in patients with advanced small intestinal neuroendocrine neoplasms. Nutr Cancer. 2021;73(9):1638-43.

5. Sowerbutts AM, Lal S, Sremanakova J, Clamp A, Todd C, Jayson GC, et al. Home parenteral nutrition for people with inoperable malignant bowel obstruction. Cochrane Database Syst Rev. 2018;8: CD012812.

6. Arends J, Bachmann P, Baracos V, Barthelemy N, Bertz H, Bozzetti F, et al. ESPEN guidelines on nutrition in cancer patients. Clin Nutr. 2017;36(1): $11-48$.

7. Teunissen SC, Wesker W, Kruitwagen C, de Haes HC, Voest EE, de Graeff A. Symptom prevalence in patients with incurable cancer: a systematic review. J Pain Symptom Manage. 2007;34(1):94-104. 
8. Tobberup R, Thoresen L, Falkmer UG, Yilmaz MK, Solheim TS, Balstad TR. Effects of current parenteral nutrition treatment on health-related quality of life, physical function, nutritional status, survival and adverse events exclusively in patients with advanced cancer: a systematic literature review. Crit Rev Oncol Hematol. 2019;139:96-107.

9. Ivanovic N, Buche D, Fringer A. Voluntary stopping of eating and drinking at the end of life-a 'systematic search and review' giving insight into an option of hastening death in capacitated adults at the end of life. BMC Palliat Care. 2014;13(1):1.

10. Piot E, Leheup BF, Goetz C, Quilliot D, Niemier JY, Wary $\mathrm{B}$, et al. Caregivers confronted with the withdrawal of artificial nutrition at the end of life: prevalence of and reasons for experienced difficulties. Am J Hosp Palliat Care. 2015;32(7):732-7.

11. Hui D, Dev R, Bruera E. The last days of life: symptom burden and impact on nutrition and hydration in cancer patients. Curr Opin Support Palliat Care. 2015;9(4):346-54.

12. Koretz RL. Should patients with cancer be offered nutritional support: does the benefit outweigh the burden? Eur J Gastroenterol Hepatol. 2007;19(5): 379-82.

13. Del Rio MI, Shand B, Bonati P, Palma A, Maldonado A, Taboada $\mathrm{P}$, et al. Hydration and nutrition at the end of life: a systematic review of emotional impact, perceptions, and decision-making among patients, family, and health care staff. Psychooncology. 2012;21(9):913-21.

14. Druml C, Ballmer PE, Druml W, Oehmichen F, Shenkin A, Singer $P$, et al. ESPEN guideline on ethical aspects of artificial nutrition and hydration. Clin Nutr. 2016;35(3):545-56.

15. Gordon EJ, Daugherty CK. 'Hitting you over the head': oncologists' disclosure of prognosis to advanced cancer patients. Bioethics. 2003;17(2): 142-68.

16. Baile WF, Lenzi R, Parker PA, Buckman R, Cohen L. Oncologists' attitudes toward and practices in giving bad news: an exploratory study. J Clin Oncol. 2002;20(8):2189-96.

17. Sowerbutts AM, Lal S, Sremanakova J, Clamp AR, Jayson GC, Teubner A, et al. Palliative home parenteral nutrition in patients with ovarian cancer and malignant bowel obstruction: experiences of women and family caregivers. BMC Palliat Care. 2019;18(1):120.

18. Kaasa S, Loge JH, Aapro M, Albreht T, Anderson R, Bruera $\mathrm{E}$, et al. Integration of oncology and palliative care: a Lancet Oncology Commission. Lancet Oncol. 2018;19(11):e588-653.

19. Berwick DM, Hackbarth AD. Eliminating waste in US health care. JAMA. 2012;307(14):1513-6.

20. Berwick DM. Avoiding overuse-the next quality frontier. Lancet. 2017;390(10090):102-4.

21. Cardona-Morrell M, Kim J, Turner RM, Anstey M, Mitchell IA, Hillman K. Non-beneficial treatments in hospital at the end of life: a systematic review on extent of the problem. Int J Qual Health Care. 2016;28(4):456-69.

22. Eysenbach G. Improving the quality of Web surveys: the checklist for reporting results of internet E-surveys (CHERRIES). J Med Internet Res. 2004;6(3):e34.

23. Braun V, Clarke V. Using thematic analysis in psychology. Qual Res Psychol. 2006;3(2):77-101.

24. Froud R, Meza TJ, Ernes KO, Slowther AM. Research ethics oversight in Norway: structure, function, and challenges. BMC Health Serv Res. 2019;19(1):24.

25. Orrevall Y, Tishelman C, Permert J. Home parenteral nutrition: a qualitative interview study of the experiences of advanced cancer patients and their families. Clin Nutr. 2005;24(6):961-70.

26. Bukki J, Unterpaul T, Nubling G, Jox RJ, Lorenzl S. Decision making at the end of life-cancer patients' and their caregivers' views on artificial nutrition and hydration. Support Care Cancer. 2014;22(12): 3287-99.

27. Wheelwright SJ, Hopkinson JB, Darlington A-S, Fitzsimmons DF, Fayers P, Balstad TR, et al. Development of the EORTC QLQ-CAX24, a questionnaire for cancer patients with cachexia. J Pain Symptom Manage. 2017;53(2):232-42.

28. Aaronson NK, Ahmedzai S, Bergman B, Bullinger M, Cull A, Duez NJ, et al. The European Organization for Research and Treatment of Cancer QLQ-C30: a quality-of-life instrument for use in international clinical trials in oncology. J Natl Cancer Inst. 1993;85(5):365-76.

29. Groenvold M, Petersen MA, Aaronson NK, Arraras JI, Blazeby JM, Bottomley A, et al. The development of the EORTC QLQ-C15-PAL: a shortened questionnaire for cancer patients in palliative care. Eur J Cancer. 2006;42(1):55-64.

30. Salonen BR, Mundi MS, Hurt RT, Bonnes SL. The role of parenteral nutrition for incurable cancer: bridging expectations and reality. Curr Nutr Rep. 2021;10(3):226-31. 
31. Roeland EJ. Cancer cachexia: the elephant in the room? J Cachexia Sarcopenia Muscle. 2022;13(1): 3-4.

32. Amano K, Maeda I, Morita T, Masukawa K, Kizawa $\mathrm{Y}$, Tsuneto $\mathrm{S}$, et al. Beliefs and perceptions about parenteral nutrition and hydration by family members of patients with advanced cancer admitted to palliative care units: a nationwide survey of bereaved family members in Japan. J Pain Symptom Manage. 2020;60(2):355-61.
33. Leheup BF, Piot E, Goetz C, Quilliot D, Niemier J-Y, Wary $B$, et al. Withdrawal of artificial nutrition: influence of prior experience on the perception of caregivers. Am J Hosp Palliat Med. 2015;32(4): 401-6.

34. Liposits G, Orrevall Y, Kaasa S, Österlund P, Cederholm T. Nutrition in cancer care: a brief, practical guide with a focus on clinical practice. JCO Oncol Pract. 2021;17(7):e992-8. 